\title{
IS INCOMPATIBILISM COMPATIBLE WITH FREGEANISM?
}

\author{
NILS KÜRBIS
}

King's College London

Original scientific article - Received: 09/11/2018 Accepted: 11/02/2019

\begin{abstract}
This paper considers whether incompatibilism, the view that negation is to be explained in terms of a primitive notion of incompatibility, and Fregeanism, the view that arithmetical truths are analytic according to Frege's definition of that term in $\$ 3$ of Foundations of Arithmetic, can be held together. Both views are attractive in their own right, in particular for a certain empiricist mind-set. They promise to account for two philosophical puzzling phenomena: the problem of negative truth and the problem of epistemic access to numbers. For an incompatibilist, proofs of numerical non-identities must appeal to primitive incompatibilities. I argue that no analytic primitive incompatibilities are forthcoming. Hence incompatibilists cannot be Fregeans.
\end{abstract}

Keywords: Analyticity, arithmetic, falsity, incompatibility, negation

\section{The Problem of Negation and Negative Truth}

Some philosophers find negation problematic. It is not difficult to appreciate why. Nothing really corresponds to negation. Nowhere do you encounter negativity: you do not perceive that the sky is not green, that there is no beer in the fridge, that this Riesling is not dry, that this is box does not weigh $5 \mathrm{~kg}$. You encounter just what is the case, not also what is not the case. What you see is that the sky is blue, you check what is in the fridge and there is only a bottle of wine, you taste the sweetness of the wine, you weigh the box and the scales' indicator comes to rest at $3 \mathrm{~kg}$. 
There is only what there is, not also what there is not. So how can we speak truly about the world using negative propositions?

The problem of negation or negative truth has been acutely felt by empiricists. For words to be meaningful, they have to denote something positive, as all that we perceive is positive. Thus the meanings of negative expressions must be derivative of and stem from the meanings of positive ones, and negative truths must be secondary to and explained in terms of positive truths. Hobbes expresses this thought in his Elements of Philosophy:

The positive names are prior to the negative ones, because, unless the former existed beforehand, there could be no use of the latter. (Hobbes 2000, Part 1, Chapter 2, §7)

Locke concurs and writes that

negative or privative words cannot be said properly to belong to, or signify no ideas: for then they would be perfectly insignificant sounds; but they relate to positive ideas, and signify their absence. (Locke 1979: Book III, Chapter 1, §4)

Ayer, grappling with the distinction between negative and affirmative statements, concludes that, although negative statements cannot be reduced to affirmative ones because the former are less specific than the latter,

logically a negative statement $[\ldots]$ can be verified only through the truth of some more specific statement which entails it; a statement which will itself, by contrast, be counted as affirmative. (Ayer 1952, 815)

Ayer continues, drawing attention to a metaphysical aspect of his conclusion, that

in the same way we can account for the inclination that many people have towards saying that reality is positive. The explanation is that any information which is provided by a less specific statement will always be included in the information provided by some more specific statement. (Ibid.)

Ayer describes this inclination quite neutrally, which indicates that, although a particularly natural component of the empiricist line of thought, the view is attractive also before other metaphysical backgrounds. 


\section{Incompatibilism}

One attempt at explaining negative truth or negation in terms of positive notions is almost immediately forthcoming. If the sky is blue, then it is not green, because being blue excludes it from being green; if the fridge is full of wine, its contents exclude bottles of beer from being in it; the sweetness of the wine excludes it from being dry; if something weighs only $3 \mathrm{~kg}$, this excludes it from weighing $5 \mathrm{~kg}$. Negation can be explained in terms of what things are and what properties exclude each other or which properties are incompatible with each other. For ' $a$ is not $F$ 'to be true, it suffices for $a$ to have a property $G$ which is incompatible with $F$. The puzzle dissolves, because negation is not a primitive concept, but one that is explained in terms of incompatibility.

Demos offers an extended discussion of the problem of negation and its solution in terms of a primitive notion of incompatibility in an empiricist setting. According to Demos, "a negative proposition constitutes description of some true positive proposition in terms of the relation of opposition which the latter sustains to some other positive proposition" (Demos 1917, 194), where opposition is the notion of incompatibility introduced in the last paragraph. More recently, Huw Price has argued in a similar spirit that "the apprehension of incompatibility [is] an ability more primitive than the use of negation" (Price 1990, 226). Price, like Demos, proposes to explain negation in terms of incompatibility:

It is appropriate to deny a proposition $P$ (or assert $\sim P$ ) when there is some proposition $Q$ such that one believes that $Q$ and takes $P$ and $Q$ to be incompatible. (Ibid. 231)

I call the view that negation is to be explained in terms of a primitive notion of metaphysical incompatibility incompatibilism. ${ }^{1}$

Let's put some more flesh on incompatibilism. Russell $(1951,297)$ reports that Wittgenstein once refused to accept that there was no hippopotamus in a lecture room in Cambridge. Neither is there a hippopotamus in the

\footnotetext{
${ }^{1}$ Price appeals to a further primitive in his explanation of negation, namely a primitive speech act of denial. The crucial thought, however, is that negation is based on incompatibility. Negation, according to Price $(2019,6)$, is needed only for pragmatic reasons, to enable speakers to register explicitly and to convey to other speaker that they consider two propositions to be incompatible. Similarly, Rumfitt (2000) appeals to a notion of incompatibility, albeit between speech acts, rather than propositions, in his bilateral account of logic. Restall (2005, 6ff), too, appeals to a notion of incoherence, that of asserting and denying the same proposition.
} 
room I am in now. Cheyne and Pigden explain that the "great big positive fact (or collection of facts)" the room as it actually is makes it true that there is no hippopotamus in it. Their "claim is that the existence of this fact [...] necessitates or makes true the proposition that there is no hippopotamus in the room" (Cheyne and Pigden 2006, 255). Had there been a hippo in the room, that fact would not have existed. Containing intact furniture, books on shelves, an unscathed philosopher etc., is incompatible with a room containing a hippo. The things or facts there are suffice to explain negative truths. As another example, suppose Theaetetus is not flying, but sitting next to Socrates. Then

the big fact (or collection of facts) that we can roughly characterize as Theaetetus as he actually is necessitates the truth of [Theaetetus is not flying]. For if Theaetetus were flying this fact would not exist. Thus positive facts constituting what Theaetetus is doing necessitate negative truths about what he is not doing. (Ibid., 259)

Negative truth is explained in terms of the things there are and what they exclude or with what they are incompatible.

Veber, too, emphasises that very large, positive, facts, are the truthmakers of negative truths.

If the truth of $Q$ is incompatible with the truth of $P$ then $P$ will entail Not- $Q$ and thus $P$ 's truthmaker will function as Not- $Q$ 's truthmaker as well. Provided that every negative truth is entailed by some set of positive truths with positive truthmakers, negative truths can be made true by positive facts. (Veber 2008, 82)

That neither the Great Wall of China nor a golf ball are in my coffee cup is due to certain positive facts. In the first case, "that the cup has certain dimensions and that the Wall has certain dimensions are metaphysically incompatible with the Wall being contained in the cup" (Veber 2008, 83). The dimensions of the cup and the Great Wall of China are positive facts. Concerning the golf ball and the cup, "truths about the distribution of air (or coffee) molecules inside the cup" and what the golf ball is made of are incompatible with the golf ball being in the cup. Golf balls are made of "rubber or hard plastic" and that "an air (or coffee) molecule is located in a certain place at a certain time is incompatible with a molecule of rubber or hard plastic being there" (Veber 2008, 83). Thus, only positive facts and what they are incompatible with are needed as the truthmakers of the negative truth that there is no golf ball in my coffee cup. 
The view that negation can be explained in terms of incompatibility is interesting, well motivated and attractive. To put it more sharply into focus and to illustrate the advantages of the incompatibilist view, let's compare it briefly with the solution that Russell favoured at some point in his thinking: that there are negative facts. ${ }^{2}$

\section{Against Negative Facts}

Russell argued that there are two kinds of facts.

Let us suppose, for the sake of illustration, that $x$ has the relation $R$ to $y$, and $z$ does not have the relation $S$ to $w$. Each of these facts contains only three constituents, a relation and two terms; but the two facts do not have the same form. In the one, $R$ relates $x$ and $y$; in the other, $S$ does not relate $z$ and $w$. It must not be supposed that the negative fact contains a constituent corresponding to the word "not." It contains no more constituents than a positive fact of the correlative positive form. The difference between the two forms is ultimate and irreducible. We will call this characteristic of a form its quality. Thus facts, and forms of facts, have two opposite qualities, positive and negative. (Russell 1919a, 4)

Russell argued that Demos' view has no methodological advantage, and in fact some disadvantages, over the view that there are negative facts, and that it is circular, if the aim is to avoid negative notions, as incompatibility is itself negative (Ibid., 5f).

Not many philosophers are satisfied with the view that there are negative facts. Even Russell himself was not entirely convinced: in The Philosophy of Logical Atomism (Russell 1919b, 42), Russell is less committal and merely asks his audience to consider the possibility that there are negative facts in addition to positive ones.

Demos aimed to explain negative true propositions without having to introduce negative facts. According to Demos,

the reason why such a view must not be entertained is the empirical consideration that strictly negative facts are nowhere to be met with in experience, and that any knowledge of a negative nature seems to be derived from perception of a positive kind. (Demos 1917, 189)

\footnotetext{
${ }^{2}$ The discussion of negative facts was added at the request of a referee.
} 
A congenial view is expressed by Grzegorczyk in a paper giving an interpretation of intuitionist logic as the logic of scientific research: the atomic sentences of the language are established as true or otherwise by a method of enquiry, while

the compound sentences are not a product of experiment, they arise from reasoning. This concerns also negations: we see that the lemon is yellow, we do not see that it is not blue. (Grzegorczyk 1964, 596)

The negations of sentences are not verified directly, but their verification involves reasoning. ${ }^{3}$

Another reason to reject the existence of negative facts is that for each positive fact there are uncountably many negative facts. There would be, besides the facts of the contents of my room, also the negative facts that there is no hippo in it, no rhinoceros, no blackbird, no giraffe, besides the facts of its location, there would also be the negative facts that it is not in Madrid, not in Paris, not in Berlin, not in Warsaw etc. That is just too many facts. It is a demand of ontological economy that if the phenomena can be explained without appeal to negative facts, then this is what we should do. Arguably, an account such as Cheyne's and Pigden's or Veber's succeeds in doing precisely that, and so the existence of negative facts should be rejected.

Another reason against accepting negative facts is the following. Suppose the cat is on the mat. Then that fact can be said to be located where the cat and the mat are. But suppose the cat is not on the mat. Where is the negative fact located? Where the cat is? Where the mat is? Where both are? Neither answer is particularly attractive. Negative facts do not appear to be located anywhere. But something that is not located in space presumably also cannot enter the causal nexus of the world. Negative facts would then not do any causal work and have no causal effects on the world, and as such, on plausible metaphysical assumptions about causality and the physical world, they would not be part of it. Negative facts would serve no purpose in the world, but they were introduced as supposedly on a par with positive facts, which undoubtedly serve a purpose. ${ }^{4}$

Incompatibilism is a view as general as the problem it aims to solve. The problem of negative truth isn't one exclusively for empiricists. Some philosophers may simply share the sentiments Mumford expresses,

\footnotetext{
${ }^{3}$ I owe the reference to Grzegorczyk to a referee for this journal.

${ }^{4}$ For further development of this argument, see Molnar (2000, 76ff).
} 
according to whom negative facts, to which negative truths would appear to correspond, are

too mysterious to be taken seriously. ['Everything that exists is positive'] has almost a ring of aprioricity about it. How can these facts exist and be negative? Indeed, how can any existent really be negative? (Mumford 2007, 49)

Mumford's description is, just like Ayer's quoted earlier, quite neutral, which indicates that the problem is not specifically tied to a correspondence theory of truth either. Existence itself seems to be essentially positive. Nothing negative exists. The problem of negative truth is a very ancient and general one. A closely related problem, the problem of how there can be false speech or thought, posed itself already to Parmenides, who warns us that

never shall this be forcibly maintained, that things that are not are, but you must hold back your thought from this way of enquiry, nor let habit, born of much experience, force you down this way, by making you use an aimless eye or an ear and tongue full of meaningless sound: judge by reason the strife-encompassed refutation spoken by me. (Kirk, Raven and Schofield 1983, 248, Fragment 294)

Parmenides concludes: "What is there to be said and thought must needs be: for it is there for being, but nothing is not" (Ibid., 247, Fragment 293). But then 'false speech' or 'false thoughts' are meaningless and neither speech nor thought at all. The ancient problem of falsity received profound systematic treatment and conceptual clarification by Plato. In the middle section of the Sophist, the Eleatic Stranger is lead to commit "the patricide of father Parmenides" and to "insist by brute force both that that which is not somehow is, and then again that that which is somehow is not" (Plato 1997, 241d). In the Euthydemos, Socrates encounters two sophists who deny the possibility of false thoughts and disagreement. ${ }^{5}$ Plato's vivid presentation of the perplexities surrounding negation, falsity and negative truth challenges philosophers of any background to address the problem. The issues discussed here apply to a wider range of positions than just some

\footnotetext{
${ }^{5}$ For a commentary on the Euthydemos, see McCabe (forthcoming). I comment on the commentary in the same volume.
} 
forms of empiricism. For the purposes of illustration, however, I confine consideration to empirically minded philosophers. ${ }^{6}$

\section{Fregeanism}

Reference to and knowledge about numbers is also something many philosophers have found problematic, maybe even more so than negation. This, too, is a problem that is particularly acute for empiricists, for whom reference and knowledge must ultimately be explained in terms of sense perception and causal relations between speakers or thinkers and objects referred to or known about. We do not experience numbers in sense perception and we cannot stand in causal relations to them, as they are abstract objects. So how can we refer to them, let alone know anything about them? Maybe empiricists are even forced to admit that there are no numbers at all, which makes the ubiquity, usefulness and applicability of propositions apparently about them even more of a mystery.

Frege, although himself not touched by empiricist worries, formulated an attractive starting point for a solution. The logicist view that arithmetical truths are analytic opens up prospects for explaining how we manage to refer to numbers even though they are abstract objects by explaining numerical identities in terms of one-to-one correlations, or even of explaining away reference to numbers altogether. According to the characterisation of numerical identity that Frege attributes to Hume in Foundations of Arithmetic $\S 63$, the number of $F$ s equals the number of $G$ s if and only if there is a one-to-one correspondence between the $F$ s and the $G$ s. Letting \# abbreviate 'the number of' and $\exists$ ! 'there is exactly one', what is often called Hume's Principle has the following formalisation: $\# x F x=\# x G x \equiv \exists R(\forall x(F x \rightarrow \exists ! y(G y \& R x y)) \& \forall y(G y \rightarrow \exists ! x(F x \& R x y)))$

\footnotetext{
${ }^{6}$ There are of course also empirically minded philosophers who have no problem with negation. I have already mentioned Russell. Aristotle, too, has no qualms about appealing to negation in the formulation of the most certain and fundamental principle in Metaphysics $\Gamma .3$, that "the same attribute cannot at the same time belong and not belong to the same subject in the same respect" (Aristotle 1985, 1005ba19-20). Mill also belongs to this group: "When the positive name is connotative, the corresponding negative name is connotative likewise; but in a peculiar way, connoting not the presence but the absence of an attribute. Thus, not-white denotes all things whatever except white things; and connotes the attribute of not possessing whiteness. For the non-possession of any given attribute is also an attribute, and may receive a name as such; and thus negative concrete names may obtain negative abstract names to correspond to them" (Mill 1882, 41f). For opposition to the incompatibilist account of negation, see Armstrong (2004, 55ff), Kürbis (2019, Ch. 4), Molnar (2000), Taylor (1952, 1953). The last paper is a response to a paper of Ayer's on negation quoted earlier. For a commentary on Molnar's paper, see Kürbis (2018).
} 
For ease of exposition, we can additionally require that $\forall \mathrm{x} \forall \mathrm{y}(R x y \rightarrow F x$ \& $G y$ ), so that $R$ is a relation the domain of which are the $F$ s and the range of which are the $G$ s.

Russell's version of logicism was sympathetic to empiricism. Carnap explicitly thought that logicism provides an approach to solving the problem of reference to numbers in an empiricist setting. Carnap describes how he

had learned from Frege that all mathematical concepts can be defined on the basis of the concepts of logic and that the theorems of mathematics can be deduced from the principles of logic. Thus the truths of mathematics are analytic in the general sense of truth based on logic alone. [...] It became possible for the first time to combine the basic tenet of empiricism with a satisfactory explanation of the nature of logic and mathematics. (Carnap 1963, 46f)

Hale and Wright developed Frege's thoughts in a direction which, although they themselves may not be motivated purely by empiricist worries either, can plausibly be appropriated by empiricists. Their aim is to explain

how statements of a given kind can be understood as involving reference to abstract objects and can yet remain, at least in principle, humanly knowable, given that the objects they concern are outside space and time and in consequence can stand in no sort of epistemologically relevant, causal relations to human knowers. [...] A statement of numerical identity---in the fundamental case, a statement of the kind: the number of $F \mathrm{~s}=$ the number of $G s$---is true, if true, in virtue of the very same state of affairs which ensures the truth of the matching statement of one-to-one correspondence among concepts, and may be known a priori if the latter may be so known. (Hale and Wright 2002, 118f)

Despite Frege's own nonchalance regarding epistemological concerns, logicism provides philosophers reluctant to posit a special faculty of the mind to account solely for our capacity of reference to and knowledge about numbers, be it Kantian or Gödelian intuition, with an attractive account of how we, as physical beings situated in space and time, nonetheless manage to have epistemic access to numbers.

In Foundations of Arithmetic, Frege also provided appealing definitions of a priori, a posteriori, synthetic and analytic: 
It is necessary to find a proof [of a proposition] and to follow it down to the primitive truths. If in that process all that is met with are the general logical laws and definitions, then the truth is analytic [...] If, however, it is not possible to give a proof without appealing to truths which are not of the general logical kind, but are related to a special field of knowledge, then the sentence is synthetic. For a truth to be a posteriori we require that its proof cannot proceed without appealing to facts, i.e. to unprovable truths without generality that contain statements about specific objects. If, on the other hand, it is possible to give a proof from purely general laws that can neither be proved nor stand in need of proof, then the truth is a priori. (Frege $1990, \S 3)$

For want of a better term, I shall call the view that arithmetical truths are analytic in Frege's sense Fregeanism. The terminology is not supposed to suggest that Fregeanism incorporates all of Frege's philosophy. It is only a thesis on the nature of mathematical truths and the definitions of a priori, a posteriori, synthetic and analytic. In my terminology, Frege is of course a Fregean, but Fregeans need not accept all of Frege's views. The most promising way of spelling out Fregeanism is to count Hume's Principle as analytic, but philosophers who accept Hume's Principle as analytic need not be Fregeans in my terminology, if they do not accept Frege's definition of analyticity.

Fregeanism is independent of empiricism. However, as Carnap's position or an empiricist Neo-Fregeanism are well motivated, for the purposes of this essay I am interested in an empirically minded Fregean. I do not require my empiricist to reject the existence of abstract objects outright, but only that he does not accept their existence lightly: a philosopher who demands a strong argument, ideally a proof, before accepting the existence of a particular kind of abstract object, and hence who does not just accept that there are numbers, but demands that this must be established.

\section{Incompatibilist Fregeanism}

Fregeanism and incompatibilism deserve and have received serious consideration. They are initially plausible and provide promising ways of accounting for philosophically puzzling phenomena, especially in a 
broadly empiricist setting. Some philosophers may wish to accept both views. I will argue that, attractive though it is, this position is problematic. ${ }^{7}$

Consider ' $a$ is red and green all over'. By Frege's definition, it is neither synthetic nor analytic, neither a priori nor a posteriori, as it is not true: being red is incompatible with being green all over. Only true propositions are classified by Frege's definition: false propositions do not have proofs, and to classify a proposition, it is necessary to find a proof of it, says Frege. That is slightly unusual, but it is merely a slightly unusual use of terminology. We can amend the definition by stipulating that false propositions belong to the same categories as their negations.

The axioms of logic are a priori. Axioms of logic are propositions which can neither be proved nor do they stand in need of proof (from something else), while at the same time they are proved from purely general laws: they are their own one-step proofs. The same can be said of 'Being red is incompatible with being green all over'. It is a primitive, general law expressing a truth that anyone who has mastered the concepts 'red' and 'green' is in a position to recognise. Thus it is a priori. But its (one-step) proof is related to a special field of knowledge, namely colours, so it is synthetic. ${ }^{8}$ Arguing indirectly, 'Being red is incompatible with being green all over' cannot be anything but synthetic a priori. It is not a posteriori, as it does not contain reference to specific objects. It does not follow from

\footnotetext{
${ }^{7}$ My aim is to map out logical space and assess the general prospects for combining two views, while avoiding the details of how any particular philosopher might combine them. The possibility of combining incompatibilism and Fregeanism has not attracted much attention in the literature. However, Neil Tennant accepts both, logicism and incompatibilism (see Tennant 1987, 1999, 2009). Various members of audiences to whom I presented this paper have expressed sympathy for the combination. I'll say a few words about Tennant in a later footnote. Although Tennant's approach is attractive and elegant, discussing it in more detail here would distract from what is at issue. His explanations of concepts of arithmetic may strike some readers as problematic for reasons independent of my concerns in this paper, as he appears to define the concept 'the number of' and ' 0 ' at the same time.

${ }^{8}$ This is plausible independently of Frege's definitions. Maybe most people who accept that there are synthetic a priori truths agree that "Being red is incompatible with being green all over" is an example. On a Kantian definition, it is synthetic, because is incompatible with being green all over is "outside the concept" being red and it "add[s] to the concept of the subject a predicate which has not been in any wise thought in it, and which no analysis could possibly extract from it" (Kant 2010, A 7/B 11). Having grasped the concepts red, green and incompatible suffices to grasp that being red is incompatible with being green. It is something that "our faculty of knowledge supplies from itself", hence it is a priori. Besides, "Being red is incompatible with being green all over" carries with it a kind of necessity that, according to Kant, a posteriori knowledge cannot have.
} 
only general logical laws and definitions, so it is not analytic. Assuming every truth can be classified by Frege's definitions, it is synthetic a priori.

If establishing the incompatibility of $F$ and $G$ appeals to a special field of knowledge concerning the properties $F$ and $G$, then 'Being $F$ is incompatible with being $G$ 'is synthetic a priori. Frege's definitions assume that if there is a proof of a proposition, there is one in which every step is made explicit according to the axioms of the system and the additional assumptions necessary to derive the proposition. If negation is defined in terms of incompatibility, any such fully analysed proof of a proposition $\sim A$ must appeal to propositions about incompatibilities. If these propositions are synthetic, $\sim A$ itself is synthetic.

A Fregean can employ an axiomatisation of logic in which negation is primitive. The incompatibilist needs to adopt one in which incompatibility is primitive. Proofs in second-order logic plus Hume's Principle remain valid for the incompatibilist Fregean, but they require analysis into more basic steps where any appeal to negation is replaced by an appeal to incompatibility. As by the Fregean definition fully analysed proofs are decisive for establishing whether a proposition is analytic or synthetic, $a$ priori or a posteriori, although arithmetical propositions certainly remain a priori, because the newly analysed proofs will only appeal to purely general laws that can neither be proved nor stand in need of proof, to ensure that they remain analytic, the incompatibilist Fregean needs to avoid appeal to propositions that refer to a specific field of knowledge. Incompatibilism is motivated by examples such as 'Being red is incompatible with being green', which involve properties of physical objects. These would not do for arithmetic, as arithmetic is not tied to the existence of colours. An incompatibilist could extend the account of negation to arithmetic by appealing to primitive incompatibilities involving the numbers, such as 'Being identical to 1 is incompatible with being identical to 2'. However, these appeal to a special field of knowledge, namely the numbers, and thus any proposition proved by appeal to them would be synthetic. Thus this route is not open to the Fregean incompatibilist. The fundamental idea of Frege's logicism was that names referring to numbers are not primitive, but defined in purely logical terms. In other words, the Fregean incompatibilist must assume that there are propositions of the form 'Being $F$ is incompatible with being $G$ ' which are analytic, i.e. that there are purely logical properties that are incompatible with each other. 


\section{Are there Analytic Incompatibilities?}

As numerical identities are explained in terms of Hume's Principle, we might expect numerical non-identities to be provable on the basis of incompatibilities involving one-to-one mappings. Let's consider an example of the kind Frege uses to motivate his account. Suppose you're laying the table. You map the knives and forks one-to-one onto each other and attempt to map them one-to-one onto the plates. You fail and one plate is left over. You have discovered that the forks and knives are equinumerous, but that the plates are not equinumerous to them. Trying to express the non-identity 'The number of plates is not identical to the number of knives' in terms only of what things are and incompatibility, we could say that being that left over plate is incompatible with being mapped onto a knife and fork. Generalising, attempting to map $F$ s and $G$ s one-toone onto each other leads sometimes to success, sometimes to frustration. If the number of $F \mathrm{~s}$ is not identical to the number of $G \mathrm{~s}$, attempting to map the $F$ s one-to-one onto the $G$ s will always leave some $G$ s or $F$ s out.

Arithmetic cannot be based on an activity of mapping, anymore than it can be based on the activity of laying the table. If we appeal to a mental faculty of carrying out such mappings or mathematical constructions in the abstract, it looks as if we once more appeal to a special field of knowledge, so that propositions about incompatibilities between sizes of sets turn out to be synthetic. The incompatibilist Fregean should follow a similar path to Frege's and use the example as purely heuristic to motivate a general account suitable for the foundations of arithmetic. Following this line of thought, the incompatibilist Fregean needs to specify purely logical primitive incompatibilities between sizes of sets that can be appealed to in establishing numerical non-identities.

Let's assume that there are more $G$ s than $F$ s. Then for any one-to-one relation $R$ with the $F$ s as domain, for every $F$, there is exactly one $G$ such that $R$ relates them, but there are some $G$ s which are not identical to any of those that are related by $R$ to an $F$. The incompatibilist Fregean needs a general characterisation of one-to-one relations that map the $F$ s into but not onto the $G$ s in terms of incompatibility and without using negation. It must apply to all cases in which there is no one-to-one relation between $F$ s and $G$ s. Only then can we expect to be able to prove that such incompatibilities hold, independently of being able to carry out certain constructions or not. It is not enough to say that assuming there to be a oneto-one correlation entails two incompatible statements: what these might be is precisely the question we are trying to answer. The incompatibilities we are looking for need to be general, so we cannot rely on some 
characterisation involving the particular natures of the $F \mathrm{~s}$ and the $G$ s. It would be too general to lay down that 'Being one of the $F$ s is incompatible with being one of the $G \mathrm{~s}$ ', which is true if there are as many green as there are red things. We might try the following: If for any relation $R, R$ 's being a one-to-one mapping onto the $F$ s is incompatible with $R$ 's being a one-toone mapping onto the $G$ s, we can conclude that there is no one-to-one mapping of the $F$ s onto the $G$ s and that the number of $F$ s is not identical to the number of $G$ s. This, though, is not an incompatibility that can simply be appealed to in a proof: it is itself the kind of thing that stands in need of proof.

Let's go back to the heuristic point that some $G$ s are 'left over' by any oneto-one mapping $R$ of the $F \mathrm{~s}$ into the $G$ s. Being one of those $G \mathrm{~s}$ is incompatible with $R$ mapping an $F$ to it. This isn't good enough, as we cannot always indicate the $G$ s, but it shows that we need to draw a general distinction between two kinds of $G$ s: between those such that $R$ maps some $F$ to them and the others. The problem the incompatibilist faces is that they cannot use negation, as we normally would, to draw general distinctions. The most obvious differentiation between the two kinds of $G \mathrm{~s}$ is that one kind of $G$ is such that $R$ relates an $F$ to them, while the other $G$ s are not of that kind, but that makes use of negation. We might try the following: being one of the $G$ s to which $R$ relates an $F$ is incompatible with being one of the other $G$ s. But that still requires a specification of a way of establishing the otherness of those $G$ s, and besides, what could 'being other' mean other than 'not being identical to any of those'. As a final attempt, for any oneto-one relation $R$, there is a $G$ such that being the value of $R$ for an $F$ is incompatible with being it. But even waiving worries about what 'being incompatible with being it' might mean, the problem remains of how to establish in general that this is the case for a given $G .^{9}$

To solve these difficulties, the incompatibilist Fregean might introduce a further notion: difference. We can then say there are some $G$ s which are different from those $G$ s such that $R$ relates an $F$ to them. Doing so is of course to admit that incompatibility alone is insufficient, as a further

\footnotetext{
${ }^{9}$ Tennant's system suffers from exactly this problem: his account of the "badness" of $\perp$ ties it firmly to "various ways that we understand the world simply cannot be" (Tennant 1999, 217), which are synthetic truths. No attempt is made to specify any analytic absurdities. In his formalisation of arithmetic, he helps himself to $\perp$ in the rules for 0 and for one-to-one relations into, but not onto (Tennant 1987, 277ff, cf. also Tennant 2009). The rules are of course formulated generally, but this generality does not get us any further, if it only ranges over the examples of incompatibilities given by Tennant, which are synthetic a priori.
} 
primitive is needed for a satisfactory theory. More importantly, however, there is a crucial difference between difference and incompatibility. We have introduced 'difference' merely to avoid using 'not': it has no further content than 'not identical'. By contrast, incompatibility is a rich and interesting notion: there is an attempt at giving it content independently of our interest in negation. The metaphysics of colours gives rise to some of them being incompatible with each other. Other properties exhibit a similar phenomenon. Difference, on the other hand, appears to have no other content than non-identity and as an additional primitive it is just 'not identical' rewritten into one word. The move of adding a primitive notion of difference is rather desperate. It is either $a d$ hoc or a thinly veiled appeal to negation. ${ }^{10}$

Contrary to expectation, one-to-one correspondences are not a promising source of analytic incompatibilities. But maybe there are others. Frege accepted that there are two logical objects, the True and the False, so that $\mathbf{T}=\mathbf{F}$ is a logical falsehood. However, such an approach is not congenial to an incompatibilist: if there are such objects, we might as well define negation in terms of them rather than incompatibility. It may be that an incompatibilist can accept the existence of these two logical objects, but then the burden of proof is clearly on the incompatibilist to provide such an account and establish its superiority over an account that begins with truth and falsity.

There is a more general point here. The use of classical truth tables is not congenial to the incompatibilist account. Classical truth tables appeal to independently given notions of truth and falsity. ' $A$ ' is false if and only if ' $\sim A$ ' is true, hence anyone finding negation problematic will find falsity problematic, too. The incompatibilist aims to explain negation in terms of incompatibility: $\sim A$ is true if and only if there is some true proposition incompatible with $A$. The same explanation will work for falsity, using the former equivalence. So on the incompatibilist account, falsity is to be explained, just like negation, in terms of incompatibility. Besides, Price observes that giving the meaning of negation in terms of its truth table also depends on a primitive notion of incompatibility, as it "clearly depends on

\footnotetext{
${ }^{10}$ One might even go further, as suggested by a referee, and observe that the statement that $R$ is a one-to-one correspondence between the $F$ s and the $G$ s involves an implicit appeal to negation: $R$ maps different $F$ s to different $G$ s, and to say that $x$ and $y$ are different is to say that $x$ and $y$ are not identical, which appeals to negation. Thus right from the start, a logicism building on Hume's Principle is incompatible with incompatibilism. However, an incompatibilist like Tennant would deny that the concept of one-to-one correspondence implicitly appeals to negation, as negation is not appealed to in Tennant's rules for one-toone correspondence: those rules are entirely positive.
} 
our knowing that truth and falsity are incompatible" (Price 1990, 226). Nonetheless, incompatibilism is not biased against classical logic. The references to Grzegorczyk and Tennant in the current paper may suggest that an incompatibilist view is more congenial to intuitionist, rather than classical, negation. There are, however, also incompatibilists who have no qualms about accepting classical logic. Price is one of them. Demos, Cheyne, Pigden and Veber express no hesitations about classical logic. Peacocke $(1987,163 f)$ argues that his explication of the meaning of negation in terms of primitive incompatibility validates double negation. Brandom $(2008,126 f)$ is a further example of a classicist incompatibilist.

According to an influential generalised treatment of negation discussed by Dunn, the negations of propositions are evaluated in terms of a primitive incompatibility relation $\perp$ between states, situations or possible worlds:

$\chi \vDash \sim p$ if and only if $\forall \alpha(\alpha \vDash p$ implies $\alpha \perp \chi)$

Intuitively, " $\perp$ is to be thought of as a kind of incompatibility relation, i.e., $\alpha \perp \chi$ means that $\alpha$ asserts something which $\chi$ denies" (Dunn 1993, 332). One might try to appropriate this explanation to the present case to search for analytic incompatibilities, and say that $\alpha \perp \chi$ holds in case $\alpha$ and $\chi$ contain propositions that are metaphysically incompatible. This, however, this still leaves the crucial question unanswered. $\sim p$ will only count as analytically true at a world $\chi$ if the incompatibility relation amongst worlds may hold as a matter of analytically incompatible propositions being asserted at each world. So unless analytic incompatibilities are forthcoming independently of the definition of when the negation of a proposition is true at a world, so that we can say that there are cases where $\alpha$ asserts a proposition that is analytically incompatible with a proposition that $\chi$ asserts, the definition is not going to produce analytically true negations. ${ }^{11}$

Another option for an analytic incompatibility might be 'Everything is identical to everything'. For Frege, at least, this is a logical falsehood that can be formulated without using negation. It is false because there are at least two objects, the True and the False. Even better, Hume's Principle entails that there are infinitely many objects. But this is not a suitable answer for an incompatibilist Fregean. The reason why 'Everything is identical to everything' is logically false is that there are at least two different objects. Hume's Principle only entails the existence of infinitely

11 The discussion of Dunn was added in response to a request by a referee. 
many objects if we have a means of expressing that there are different objects, and the proof appeals to negation in the definition of 0 as the number of things equinumerous to the non-self-identical ones. Even if we contrived a new concept 'being incompatible with being itself', this still leaves the question of how to secure that being equinumerous to the objects falling under that concept is not equinumerous to the number of things falling under the concept 'identical to 0 ' ${ }^{12}$ As argued, adding a primitive notion of difference to secure this is unconvincing.

As a final attempt, one might observe that in second order logic it is possible to express logical falsehoods without using negation, as the falsum constant $\perp$ is definable as $\forall p . p$, and that it is possible to prove that there are at least two different concepts or properties, one under which everything falls and one under which nothing false, so that 'All concepts are identical' or 'All properties are identical' can serve as an analytic falsehood that does not appeal to negation. The crux here, however, as before, lies with 'different'. 'All concepts are identical' or 'All properties are identical' is absurd only if there are two different concepts or properties, that is to say, two concepts or properties that are not identical. Besides, to say that there is a concept under which nothing falls blatantly appeals to negation. That all propositions are true is also absurd only if there are at least two different propositions, one true and one false, or one incompatible with the other. ${ }^{13}$ The former may be true as a matter of logic, but it relies on the notion of difference, hence negation, and besides, it appeals once more to independently given notions of truth and falsity, which, as argued, is no good for the incompatibilist Fregean. The latter option just reiterates the problem: those two incompatible propositions would have to be analytically incompatible to be of use to the incompatibilist Fregean, and we have not been able to find any such propositions.

\section{Conclusion}

No analytic incompatibilities are forthcoming. The conclusion suggests itself that the only propositions that are analytically incompatible are analytic propositions and their negations. ${ }^{14}$ But this is no good for the incompatibilist Fregean, who aims to define negation in terms of

\footnotetext{
${ }^{12}$ Cook and Cogburn $(2000,10 \mathrm{f})$ make a related point that defining $\sim A$ as $A \rightarrow 0=1$ is not sufficient, as there are acceptable intuitionist theories that verify the Peano Axioms, but also $0=1$.

${ }^{13}$ For further discussion of an attempt to define negation in terms of $\perp$, see Kürbis (2015).

${ }^{14}$ As observed by a referee.
} 
incompatibility and is in need of analytic incompatibilities for the foundations of mathematics. So it looks very much as if incompatibilism is incompatible with Fregeanism.

I conclude that Fregean incompatibilism, if not incoherent, has tricky questions to answer. The burden of proof is certainly on the Fregean incompatibilist to make the case that the position is tenable. Of course, it would be possible to adopt different definitions of 'analytic' and 'synthetic'. But that would not change the fact that much of arithmetic on an incompatibilist account would turn out to be synthetic according to Frege's definition. And hasn't Frege himself given good reasons against taking arithmetic to be synthetic according to his definition? ${ }^{15}$

\section{REFERENCES}

Aristotle 1985. Metaphysics. In The Complete Works of Aristotle, ed. J. Barnes, 1552-1728. Princeton: Princeton University Press.

Armstrong, D. 2004. Truth and Truth-Makers. Cambridge: Cambridge University Press.

Ayer, A. J. 1952. Negation. The Journal of Philosophy 49: 797-815.

Brandom, R. 2008. Between Saying and Doing. Oxford: Oxford University Press.

Carnap, R. 1963. Intellectual autobiography. In The Philosophy of Rudolf Carnap, ed. P. A. Schilpp, 3-84. LaSalle: Open Court.

Cheyne, C. and C. Pigden 2006. Negative truths from positive facts. Australasian Journal of Philosophy 84: 249-265.

Cook, R. T. and J. Cogburn 2000. What negation is not: Intuitionism and ' $0=1$ '. Analysis 60: 5-12.

Demos, R. 1917. A discussion of a certain type of negative propositions. Mind 26: 188-196.

Dunn, J. M. 1993. Star and perp: Two treatments of negation. Philosophical Perspectives 7: 331-357.

Frege, G. 1990. Die Grundlagen der Arithmetic. Eine logischmathematische Untersuchung über den Begriff der Zahl. Hildesheim, Zürich, New York: Olms.

Grzegorczyk, A. 1964. A philosophically plausible formal interpretation of intuitionistic logic. Indagationes Mathematicae 26: 596-601.

Hale, B. and Wright, C. 2002. Benacerraf's dilemma revisited. The European Journal of Philosophy 10: 101-129.

${ }^{15}$ I would like to thank Giulia Felappi, Keith Hossack, Guy Longworth, Eliot Michelson, Mark Textor and the referees for this journal for a number of helpful comments and suggestions. 
Hobbes, T. 2000. Elementa Philosophiae I: De Corpore. Paris: Vrin.

Kant, I. 2010. Kritik der reinen Vernunft. Hamburg: Meiner.

Kirk, G., J. Raven, and M. Schofield 1983. The Presocratic Philosophers. Cambridge: Cambridge University Press.

Kürbis, N. 2015. What is wrong with Classical Negation? Grazer Philosophische Studien 92: 51-86

Kürbis, N. 2018. Molnar on truthmakers for negative truths. Metaphysica 19: 251-257

Kürbis, N. 2019. Proof and Falsity. A Logical Investigation. Cambridge: Cambridge University Press.

Kürbis, N. forthcoming. The importance of being erroneous. Australasian Philosophical Review 3.2

Locke, J. 1979. An Essay Concerning Human Understanding. Oxford: Oxford University Press.

McCabe, M. M. forthcoming. First chop your logos ... Socrates and the sophists on language, logic and development. Australasian Philosophical Review 3.2

Mill, J. S. 1882. A System of Logic (8th ed.). New York: Harper \& Brothers. Molnar, G. 2000. Truthmakers for negative truths. Australasian Journal of Philosophy 78: 72-86.

Mumford, S. 2007. Negative truth and falsehood. Proceedings of the Aristotelian Society CVII: 45-71.

Peacocke, C. 1987. Understanding the logical constants. A realist's account. Proceedings of the British Academy 73: 153-200.

Plato 1997. Sophist. In Complete Works, ed. J. M. Cooper, 235-293. Indianapolis: Hackett.

Price, H. 1990. Why 'Not'? Mind 99: 221-238.

Price, H. 2019 . 'Not' Again. Accessed 04/02/2019. http://prce.hu/w/preprints/NotAgain.pdf

Restall, G. 2005. Multiple conclusions. In Logic, Methodology and Philosophy of Science: Proceedings of the Twelfth International Congress, eds. P. Hájek, L. Valdés-Villanueva, and D. Westerståhl, 189-205. London: King's College Publications.

Rumfitt, I. 2000. "Yes" and "No". Mind 109: 781-823.

Russell, B. 1919a. On propositions: What they are and how they mean. Proceedings of the Aristotelian Society. Supplementary Volumes 2: $1-43$.

Russell, B. 1919b. The philosophy of logical atomism. The Monist 29: 3263.

Russell, B. 1951. Obituary: Ludwig Wittgenstein. Mind 60: 297-298.

Taylor, R. 1952. Negative things. Journal of Philosophy 49: 433-449.

Taylor, R. 1953. Ayer's analysis of negation. Philosophical Studies IV: 49-55. 
Tennant, N. 1987. Anti-Realism and Logic. Truth as Eternal. Oxford: Oxford University Press.

Tennant, N. (1999). Negation, absurdity and contrariety. In What is Negation?, eds. D. Gabbay and H. Wansing, 199-222. Dortrecht: Kluwer.

Tennant, N. 2009. Natural logicism via the logic of orderly pairing. In Logicism, Intuitionism and Formalism. What has become of them?, eds. S. Lindström, E. Palmgren, K. Segerberg, and V. Stoltenberg-Hansen, 91-125. Dordrecht: Springer.

Veber, M. 2008. How to derive a 'not' from an 'is': A defense of the incompatibility view of negative truths. Metaphysica 9: 79-91. 